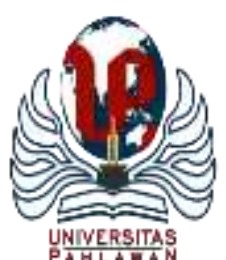

\title{
JURNALBASICEDU
}

Volume 6 Nomor 1 Tahun 2022 Halaman 364 - 371

Research \& Learningin Elementary Education

https://jbasic.org/index.php/basicedu

\section{Pengaruh Model Pembelajaran Contextual Teaching and Learning terhadap Hasil Belajar Matematika Siswa Sekolah Dasar}

\author{
Zahra Aulia Rahmah ${ }^{1 凶}$, Imas Ratna Ermawati ${ }^{2}$ \\ Pendidikan Guru Sekolah Dasar, Universitas Muhammadiyah Prof. Dr. HAMKA, Indonesia ${ }^{1,2}$ \\ E-mail: zahraa2709@gmail.com ${ }^{1}$, $\underline{\text { mas re@uhamka.ac.id }}^{2}$
}

\begin{abstract}
Abstrak
Pembelajaran matematika sangatlah penting dalam kehidupan kita sehari-hari. Melihat kondisi siswa yang merasa bosan, dan beranggapan sulit sehingga menyebabkan rendahnya hasil belajar siswa pada pembelajaran matematika. Oleh karena itu penelitian ini bertujuan untuk mengetahui adanya pengaruh penggunaan model pembelajaran Contextual Teaching and Learning terhadap hasil belajar matematika siswa kelas IV SDN Kalibang Tengah VIII. Metode penelitian yang digunakan adalah Quasy experimental dengan desain penelitian One group pret-test and post-test design. Sampel yang digunakan adalah kelas IV C sebanyak 30 siswa. Teknik pengumpulan data yang digunakan dalam penelitian ini adalah tes tertulis. Teknik analisis data uji validitas menggunakan Korelasi Point Biserial, sedangkan uji reliabilitas menggunakan KR-20. Data analisis normalitas menggunakan uji Liliefors, sedangkan homogenitas dengan menggunakan uji Fisher. Pada uji hipotesis digunakan uji-t dengan taraf signifikan $\alpha=0,05$ diperoleh $t_{\text {hitung }} 4,586$, maka dengan demikian $H_{0}$ ditolak. Hasil penelitian ini menunjukkan terdapat pengaruh yang signifikan pada pembelajaran dengan menggunakan model Contextual Teaching and Learning terhadap hasil belajar matematika siswa kelas IV SDN Kaliabang Tengah VIII.
\end{abstract}

Kata Kunci: hasil belajar, contextual teaching and learning, matematika.

Abstract

Learning mathematics is very important in our daily life. Seeing the condition of students who feel bored, and think it is difficult, causing low student learning outcomes in learning mathematics. Therefore, this study aims to determine the effect of the use of the Contextual Teaching and Learning learning model on the mathematics learning outcomes of fourth grade students of SDN Kalibang Tengah VIII. The research method used is quasi experimental with a research design of One group pret-test and post-test design. The sample used is class IV C as many as 30 students. The data collection technique used in this study was a written test. The data analysis technique used to test the validity of using Biserial Point Correlation, while the reliability test used KR-20. Data analysis of normality using Liliefors test, while homogeneity using Fisher's exact test. In the hypothesis test, a t-test was used with a significant level of $=0.05$, it was obtained that t_count was 4,586, so H_O was rejected. The results of this study indicate that there is a significant effect on learning using the Contextual Teaching and Learning model on the mathematics learning outcomes of fourth grade students at SDN Kaliabang Tengah VIII.

Keywords: learning outcomes, contextual teaching and learning, mathematics.

Copyright (c) 2022 Zahra Aulia Rahmah, Imas Ratna Ermawati

$\triangle$ Corresponding author :

Email : zahraa2709@gmail.com

DOI : https://doi.org/10.31004/basicedu.v6i1.1916

ISSN 2580-3735 (Media Cetak)

ISSN 2580-1147 (Media Online) 


\section{PENDAHULUAN}

Kegiatan belajar mengajar dilakukan bertujuan untuk menghasilkan perubahan dalam pengetahuan dan keterampilan pada siswa. Salah satu ilmu pengetahuan dan keterampilan yang harus dikembangkan adalah pembelajaran matematika. Matematika sebagai salah satu mata pelajaran sekolah dasar, matematika memegang peranan penting dalam kehidupan sehari-hari siswa (Kistian, 2018).

Menurut Siagian dalam (Lestari, 2015), matematika adalah mata pelajaran utama di sekolah dasar atau menengah. Mempelajari matematika itu sangat penting karena kita tidak dapat menghindari penerapan matematika dalam kehidupan sehari-hari. Dalam matematika terdapat banyak rumus-rumus, angka-angka, dan pastinya perhitungan-perhitungan (Novitasari, 2017). Namun matematika bisa berupa teori dan praktek. Matematika membutuhkan pengetahuan dan keterampilan untuk menyelesaikan masalah.

Perubahan pengetahuan dan keterampilan dapat dicapai setelah individu melalui suatu proses pembelajaran. Menurut Syah dalam (Jihad, 2013), pada dasarnya pembelajaran merupakan tahapan perubahan perilaku siswa yang relatif aktif dan stabil karena adanya interaksi dengan lingkungan yang melibatkan proses kognitif. Perubahan tingkah laku dapat membentuk kebiasaan dan mengembangkan keterampilan seseorang dalam kehidupan sehari-harinya melalui proses belajar. Menurut R. Gagne dalam (Susanto, 2013), belajar diartikan sebagai proses mendapatkan motivasi dalam pengetahuan, keterampilan, kebiasaan dan perilaku.

Proses pembelajaran dikatakan berhasil apabila terdapat perubahan terhadap kebiasaan belajar siswa sehingga memberi perubahan pada diri siswa setelah melalui kegiatan belajar secara keseluruhan seperti ilmu pengetahuan yang bertambah, perubahan dan peningkatan pada keterampilan siswa serta perubahan sikap siswa yang menjadi kebiasaan pada setiap proses belajar. Menurut Slameto dalam Asriningtyas, Kristin, \& Anugraheni (2018) mengatakan hasil belajar merupakan hasil dari upaya yang dilakukan dalam proses kegiatan pembelajaran yang dapat diukur melalui tes untuk mengetahui perkembangan dan kemajuan siswa. Hasil belajar dapat menjadi pedoman untuk memodifikasi perilaku siswa berdasarkan penguasaan keterampilan dasar dan materi pelajaran (Siagian, 2021). Maka dari itu kemampuan siswa dapat dilihat dari hasil belajarnya setelah proses pembelajaran melalui tes-tes baik lisan maupun tulisan sehingga dapat dipantau setiap perkembangan siswa dan diharapkan adanya kemajuan dari siswa tersebut sehingga tercapainya hasil belajar yang baik.

Dalam proses pembelajaran matematika tidak banyak siswa yang dapat menyelesaikan soal matematika dikarenakan kurangnya pengetahuan dan keterampilan dalam memecahkan permasalahan dalam soal. Dalam kegiatan pembelajaran diperlukan suatu model pembelajaran untuk mencapai keterampilan atau tujuan pembelajaran yang diinginkan. Model pembelajaran merupakan rancangan yang diperlukan sebagai pedoman dalam merancang kegiatan pembelajaran di kelas (Soleha, Akhwani, Nafiah, \& Rahayu, 2021). Oleh karena itu, dalam setiap pembelajaran pembelajaran matematika sangat diperlukan alat peraga yang dapat membantu saat proses pembelajaran agar materi yang disampaikan guru mudah dipahami dan pembelajaran dapat berlangsung menyenangkan dan menarik minat siswa serta mendorong siswa untuk aktif dalam pembelajaran.

Namun melihat kondisi sekarang pembelajaran dilakukan secara daring, akibat pandemi Covid-19 yang menyebabkan semua kegiatan dan pekerjaan dilakukan dari rumah baik kantor maupun sekolah untuk mencegah penyebaran Covid-19 agar tidak semakin meningkat penyebarannya. Pada pembelajaran daring berdasarkan pengamatan yang peneliti, jika dilakukan tatap maya atau Zoom Meeting banyak siswa yang tidak mengikuti karena keterbatasan dan siswa yang mengikuti tidak aktif dalam proses pembelajaran. Karena hal tersebut, jarang dilakukannya tatap maya atau Zoom Meeting untuk memberikan penjelasan materi pembelajaran dari guru, sehingga guru memberikan tugas untuk membaca materi dan mengerjakan layihan pada LKS yang dimiliki masing-masing siswa. Akibatnya, banyak siswa kurang paham materi pembelajaran secara mandiri dan hasil belajar tidak mencapai KKM. Padahal siswa sangat memerlukan penjelasan materi agar siswa dapat menyelesaikan dan memecahkan suatu permasalahan dalam pembelajaran matematika. 
Sebagaimana diketahui dari kondisi dan permasalahan yang terjadi maka solusi dari permasalahan yang telah diuraikan diatas, yakni peneliti memilih model yang pembelajaran yang tepat inovatif untuk pembelajaran matematika dengan model pembelajaran Contextual Teaching and Learning (CTL). Model pembelajaran merupakan suatu rencana atau pola yang dapat digunakan untuk membuat dan merancang kurikulum (rencana pembelajaran jangka panjang), mengembangkan bahan ajar, dan memandu pembelajaran di dalam ruang kelas atau tempat lain (Rusman, 2018).

Dimana model pembelajaran Contextual Teaching and Learning mendorong siswa untuk mudah menghubungkan dan mengaitkan antara pengetahuan yang dimiliki dengan penerapannya dalam kehidupan sehari-hari. Menurut Nurhadi dalam (Rusman, 2018) menjelaskan bahwa pembelajaran kontekstual (Contextual Teaching and Learning) merupakan konsep pembelajaran yang dapat membantu guru menghubungkan materi yang diajarkan dengan kondisi kehidupan nyata siswa, dan mendorong siswa untuk membuat hubungan antara pengetahuan yang siswa punya dan penerapannya dalam kehidupan siswa. Tidak hanya itu Contextual Teaching and Learning juga adalah pembelajaran yang memungkinkan siswa untuk menerapkan dan mengalami apa yang diajarkan dengan merujuk pada masalah dunia nyata, sehingga pembelajaran lebih bermakna dan menyenangkan (Widyaiswara, Parmiti, \& Suarjana, 2019).

Selain itu, Menurut Jamaluddin dalam (Amalia \& Rasiman, 2019) bahwa model pembelajaran CTL adalah proses pembelajaran yang dirancang untuk membantu siswa bekerja di lingkungan nyata, menerapkan pengetahuan dan menghubungkan pelajaran dalam konteks nyata. Memiliki kesempatan untuk mengalami proses pengolahan dan pembuatan karya, sehingga siswa menjadi aktif dan kreatif, serta dapat dengan cepat memahami materi yang diajarkan oleh guru.

Berdasarkan pernyataan diatas terlihat bahwa model pembelajaran Contextual Teaching Learning (CTL) dapat membantu guru dan siswa dalam mengaitkan materi yang diketahui dengan penerapannya dalam kehidupan sehari-hari. Kunandar dalam (Fadhilaturrahmi, 2018) mengemukakan bahwa untuk memahami pembelajaran CTL dapat disimpulkan bahwa kata kunci pembelajaran CTL adalah: (1) belajar di dunia nyata, mengutamakan pengalaman nyata, (2) berpusat pada siswa, aktif, peserta didik yang kritis dan kreatif, (3) pengetahuan memiliki makna dalam kehidupan. , dekat dengan kehidupan nyata, serta perubahan perilaku dan pelatihan "manusia", (4) Siswa berlatih, tidak menghafal, Belajar bukan mengajar, pendidikan bukan mengajar, (5) Memecahkan masalah dan berpikir pada level, dan (6) Hasil belajar diukur dengan berbagai cara, bukan hanya tes.

Model Contextual Teaching and Learning (CTL) dalam implementasinya memerlukan sebuah rencana pembelajaran yang mencerminkan konsep dan komponen karakteristik dari CTL. Menurut Kemendiknas dalam (Hidayati, 2018) menyatakan terdapat 7 komponen yang menunjukkan karakteristik pembelajaran CTL : 1) Construktivism, 2) Inquiry, 3) Questioning, 4) Learning Community, 5) Modeling, 6) Reflection, 7) Authentic Assesment.

Berdasarkan permasalahan dan penjelasan yang telah diuraikan, Tujuan pada penelitian ini ialah untuk mengetahui pengaruh model pembelajaran Contextual Teaching and Learning terhadap hasil belajar Matematika Siswa Kelas IV SDN Kaliabang Tengah VIII.

\section{METODE PENELITIAN}

Penelitian ini akan dilaksanakan di SDN Kaliabang Tengah VIII. Penelitian kuantitatif ini menggunakan metode Quasy Eksperimental Design. Bentuk rancangan penelitian ini adalah One-Group Pretest-Posttest Design, yaitu eksperimen yang dilaksanakan pada satu kelompok saja tanpa kelompok pembanding. Berikut tabel One-Group Pretest-Posttest. 

Matematika Siswa Sekolah Dasar - Zahra Aulia Rahmah, Imas Ratna Ermawati

DOI: https://doi.org/10.31004/basicedu.v6i1.1916

Tabel 1. One Group Pre-Test and Post-Test Design

\begin{tabular}{ccc}
\hline $\mathrm{O}_{1}$ & $\mathrm{X}$ & $\mathrm{O}_{2}$ \\
\hline Pre-test & Treatment (perlakuan) & Post-Test \\
\hline
\end{tabular}

Keterangan :

$\mathrm{O}_{1}=$ Nilai Pre-test (sebelum diberi perlakuan)

$\mathrm{O}_{2}=$ Nilai Post-Test (sesudah diberi perlakuan)

$\mathrm{X}=$ Perlakuan yang digunakan berupa pembelajaran menggunakan model pembelajaran Contextual Teaching and Learning (CTL).

Populasi target dlam penelitian ini yaitu kelas IV SDN Kaliabang Tengah VIII, yakni dengan sampel kelas IV C sebanyak 30 siswa. Teknik pengambilan sampel pada penelitian ini yaitu menggunakan Sampling Jenuh. Sampling Jenuh adalah teknik pengambilan sampel yang semua anggota populasi digunakan sebagai sampel (Handayani \& Subakti, 2020). Dimana teknik ini menggunakan populasi yang kecil dibawah 30 orang.

Teknik pengumpulan data yang digunakan pada penelitian ini yaitu menggunakan tes tertulis (PretestPosttest) dan dokumentasi. Instrumen penelitian yang akan digunakan adalah tes tertulis berupa pilihan ganda yang terdiri dari 30 butir soal. Sebelum pengambilan data, terlebih dahulu melakukan tela'ah soal dengan dosen ahli dan guru, selanjutnya uji coba instrumen untuk mengetahui validitas dan reliabilitas butir soal dalam tes yang akan digunakan untuk penelitian. Validitas Menurut Siregar dalam (Imron, 2019) adalah menunjukan sejauh mana suatu alat ukur mampu mengukur apa yang ingin diukur. Uji Validitas yang digunakan dalam penelitian ini adalah rumus Korelasi Biserial, sedangkan Realibilitas Menurut (Siswanto, 2017) adalah taraf sampai dimana suatu tes mampu menunjukkan keajegan hasil pengukuran yang ditampakan data taraf ketetapan dan ketelitian hasil suatu tes dapat dikatakan mempunyai taraf kepercayaan yang tinggi apabila tes tersebut dapat memberikan hasil yang tetap. Uji reliabilitas pada penelitian ini menggunakan rumus KR-20.

Teknik analisis data yang digunakan dalam penelitian ini menggunakan teknik analisis statistik deskriptif dan statistik interferensial. Statistik deskriptif digunakan untuk memperoleh ukuran pemusatan seperti mean, median, modus, dan simpangan baku yang diperoleh dari hasil pre-test dan post-test. Sedangkan perhitungan statistik interferensial terdapat persyaratan analisis yakni uji normalitas menggunakan uji liliefors dan uji homogenitas menggunakan uji fisher. Perhitungan statistik interferensial digunakan untuk pengujian hipotesis. Sedangkan pengujian hipotetsis yang digunakan dalam penelitian ini dengan uji $\mathrm{t}$ dengan rumus paired simples t-test. Setelah mengitung pengujian hipotesis peneliti melakukan pengujian pengaruh menggunakan rumus Effect Size dari Cohen dalam Santoso (2010) dalam (Dini, Sulistyarini, \& Anasi Putri Tipa, 2019) untuk one group.

\section{HASIL DAN PEMBAHASAN}

Hasil analisis deskriptif statistik pada data pretest dan posttest siswa kelas IV pembelajaran matematika dengan materi FPB dan KPK dapat dilihat pada tabel dibawah ini.

Tabel 1. Statistik Deskriptif Pre-Test dan Post-Test Hasil Belajar Matematika Kelas IV

\begin{tabular}{cccccc}
\hline & N & $\begin{array}{c}\text { Nilai } \\
\text { Terendah }\end{array}$ & $\begin{array}{c}\text { Nilai } \\
\text { Tertinggi }\end{array}$ & Rata-rata & $\begin{array}{c}\text { Simpangan } \\
\text { Baku }\end{array}$ \\
\hline Pre-test & 30 & 37 & 83 & 60,23 & 12,12 \\
\hline Post-test & 30 & 56 & 97 & 84,63 & 12,30 \\
\hline
\end{tabular}


Berdasarkan tabel diatas, data pretest memperoleh nilai tertinggi 83, nilai terendah 37 dan nilai rata-rata siswa adalah 60,23. Sedangkan, data pretest memperoleh nilai tertinggi 97, nilai terendah 56 dan nilai rata-rata siswa adalah 84,63 dengan jumlah peserta didik 30 siswa. Dapat dilihat bahwa terdapat perbedaan pada hasil pretest dan posttest, dimana data pretest diambil sebelum dilakukannya perlakuan pembelajaran menggunakan model pembelajaran Contextual Teaching and Learning. Sedangkan data posttest dilakukan setelah dilakukannya perlakuan pembelajaran menggunakan model pembelajaran Contextual Teaching and Learning.

Hasil pada pengujian persyaratan yaitu uji normalitas menggunakan uji liliefors bertujuan untuk mengetaui apakah data penelitian berdistribusi normal atau tidak. Hasil uji normalitas dapat dilihat pada tabel dibawah ini.

Tabel 2. Hasil Uji Normalitas Pre-Test dan Post-Test Hasil Belajar Matematika Kelas IV

\begin{tabular}{llrrlll}
\hline No & $\begin{array}{c}\text { Data } \\
\text { Penelitian }\end{array}$ & $\mathbf{N}$ & $\boldsymbol{\alpha}$ & $\boldsymbol{L}_{\text {hitung }}$ & $\boldsymbol{L}_{\text {tabel }}$ & Ket. \\
\hline 1. & Pre-test & 30 & 0,05 & 0,1461 & 0,1617 & \multirow{2}{*}{ Normal } \\
\hline 2. & Post-test & 30 & 0,05 & 0,1562 & 0,17 \\
\hline
\end{tabular}

Terlihat dari tabel diatas bahwa uji normalitas hasil nilai pre-test untuk taraf signifikan $\alpha=0,05$, diperoleh $\mathrm{L}$ (hitung $)=0,1416$ dan $\mathrm{L}$ (tabel $)=0,1617$. Sedangkan uji normalitas hasil nilai post-test untuk taraf signifikan $\alpha=0,05$, diperoleh $\mathrm{L}$ (hitung ) $=0,1562$ dan $\mathrm{L}$ (tabel ) $=0,1617$. Karena $\mathrm{L}$ (hitung ) < $\mathrm{L}$ (tabel ), maka data penelitian menggunakan model pembelajaran Contextual Teaching and Learning berdistribusi normal.

Tahap selanjutnya yaitu uji homogenitas pada data hasil penelitian ini menggunakan uji Fisher. Uji homogenitas digunakan untuk menguji dua data sampel hasil penelitian apakah kedua sampel bersifat homogen atau tidak. Hasil pengujian homogentas dapat dilihat pada tabel dibawah ini.

Tabel 3. Hasil Uji Homogenitas Pre-Test dan Post-Test Hasil Belajar Matematika Kelas IV

\begin{tabular}{ccccccccc}
\hline No & Sampel & n & df & Var & $\boldsymbol{\alpha}$ & $\boldsymbol{F}_{\text {hitung }}$ & $\boldsymbol{F}_{\text {tabel }}$ & Ket. \\
\hline 1. & Pre-test & \multirow{2}{*}{30} & 29 & $\frac{152,047}{2}$ & \multirow{2}{*}{0,05} & $\mathbf{1 , 0 2 9}$ & $\mathbf{1 , 8 5 0}$ & \multirow{2}{*}{ Homogen } \\
\hline 2. & Post-test & & & 156,585 & & & & \\
\hline
\end{tabular}

Berdasarkan tabel diatas, dapat dilihat bahwa uji homogenitas pada kedua sampel yaitu pretest dan posttest dengan taraf signifikan 0,05, diperoleh Fhitung $=1,029$ dan Ftabel $=1,850$. Karena Fhitung $<$ Ftabel, maka data hasil nilai pretest dan posttest dinyatakan homogen.

Setelah data yang sudah diuji normalitas dan homogenitas menunjukkan data pretest dan posttest berdistribusi normal dan homogen. Langkah selanjutnya, pengujian hipotesis digunakan untuk mengetahui apakah terdapat pengaruh penggunaan model Contextual Teaching and Learning (CTL) terhadap hasil belajar matematika siswa, simpulan penelitian dan hipotesis diterima. Berdasarkan uji persyaratan analisis, maka data dianalisis menggunakan uji-t. Pengujian hipotesis menggunakan paired simples $t$-test pada taraf signifikan 0,05 . Hasil pengujian hipotesis dapat dilihat pada tabel berikut.

Tabel 4. Hasil Uji-t

\begin{tabular}{cccccc}
\hline $\mathbf{n}$ & Dk & thitung & ttabel & Keterangan & keputusan \\
\hline 30 & 29 & 4,586 & 2,045 & signifikan & $\mathrm{H}_{a}$ diterima \\
\hline
\end{tabular}

Berdasarkan hasil perhitungan uji-t pada tabel diatas dengan taraf 0,05 , diperoleh Thitung $=4,586$ dan Ttabel $=2,045$. Sehingga data penelitian menunjukkan bahwa Ha diterima dan H0 ditolak. Dengan demikian, dapat dinyatakan bahwa terdapat pengaruh model CTL terhadap hasil belajar matematika siswa SDN 
Kaliabang Tengah VIII. Setelah data yang sudah dilakukannya pengujian hipotesis menunjukkan data pretest dan posttest terdapat pengaruh oleh model pembelajaran CTL terhadap hasil belajar siswa.

Langkah selanjutnya, pengujian effect size digunakan untuk mengetahui apakah besar atau kecilnya pengaruh penggunaan model Contextual Teaching and Learning (CTL) terhadap hasil belajar matematika siswa. Hasil pengujian effect size dapat dilihat pada tabel berikut.

Tabel 5. Hasil Uji Effect Size

\begin{tabular}{ccccccc}
\hline n & $\begin{array}{c}\text { Rata-rata } \\
\text { Pre-test }\end{array}$ & $\begin{array}{c}\text { Rata-rata } \\
\text { Post-test }\end{array}$ & $\begin{array}{c}\text { Nilai } \\
\text { Effect size }\end{array}$ & $\begin{array}{c}\text { Kriteria } \\
\text { Tabel }\end{array}$ & Keterangan & keputusan \\
\hline 30 & 60,23 & 84,63 & 1,98 & $>1,00$ & Besar & $\begin{array}{c}\text { Pengaruh yang } \\
\text { besar }\end{array}$ \\
\hline
\end{tabular}

Dapat dilihat dari tabel diatas, dengan rata-rata nilai post test 84,63 dan rata-rata nilai pre test 60,23 memperoleh nilai Effect size yaitu 1,98. Dimana kriteria besar effect size > 1,00 artinya memiliki pengaruh yang besar. Jadi, dapat dikatakan bahwa terdapat pengaruh yang besar oleh model pembelajaran Contextual Teaching and Learning terhadap hasil belajar matematika siswa.

Berdasarkan hasil penelitan serta uraian diatas, dapat dinyatakan bahwa penggunakan model pembelajaran contextual teaching and learning dapat memberikan perubahan serta meningkatkan hasil belajar matematika siswa. Karena penerapan model Contextual Teaching and Learning menggunakan benda konkret atau nyata dalam proses pembelajaran agar mempermudah siswa dalam memahami konsep dari materi yang disampaikan serta siswa yang lebih banyak bekerja dan aktif tidak hanya guru yang memberikan materi berupa teori. Model ini juga lebih mengutamakan keterlibatan siswa secara maksimal dalam pembelajaran akan berdampak positif terhadap perilaku belajar siswa dan pandangan terhadap matematika sehingga model CTL ini dapat memberi siswa kelas IV SDN Kaliabang Tengah VIII dalam proses pembelajaran agar tidak merasa jenuh dan memberikan kesan yang menyenangkan serta bermakna pada pembelajaran matematika yang membuat hasil belajar siswa menjadi lebih baik. Adapun cara agar matematika tidak terlihat sulit, menurut Pound dalam (Siswono, 2012) adalah (1) Mengajar matematika sejak dini atau melahirkan anak matematika; (2) menggunakan lagu atau puisi yang menarik atau puisi berirama; (3) Menjadikannya nyata atau erat kaitannya dengan kehidupan sehari-hari.

Tahapan pelaksanaan model pembelajaran Contextual teaching and learning diterapkan pada kelas IV C SDN Kaliabang Tengah VIII yang berjumlah 30 siswa. Penelitian ini dilaksanakan berdasarkan kompetensi dasar dan indikator kompetensi hasil belajar matematika dengan materi FPB dan KPK.

Berdasarkan penelitian yang dilakukan, Sebelum memulai pembelajaran peneliti memberikan rangsangan dengan mengulang materi kepada siswa terkait materi yang akan di bahas, karena di semester sebelumnya sudah dipelajari dan diajarkan oleh guru kelasnya. Setelah mengulang materi, penliti mulai memberikan mpertanyaan seputar pokok bahasan, lalu menunjukkan alat peraga dan menghubungkannya dengan materi FPB dan KPK untuk menambah pemahaman.

Dalam setiap pertemuan selama proses pembelajaran berlangsung, siswa dengan semangat menyimak, memperhatikan dan antusias ikut serta dalam tanya jawab. Lalu peneliti juga membuat kelompok saat memberikan LKPD yang membuat siswa aktif dalam kelompok dan saling bekerja sama bertukar pikiran dalam mencari jawaban. Dengan adanya kegiatan ini dapat membuat keterlibatan dan antusias siswa dalam proses pembelajaran semakin besar, siswa bekerja sama mencari jawaban yang benar secara bersama-sama sehingga pembelajaran yang dilakukan dapat bertahan lebih lama dan bermakna.

Setelah dilakukan analisis hasil pretest dan posttest meliputi uji normalitas, uji homogenitas dan uji-t diketahui bahwa data hasil akhir terdapat peningkatan hasil belajar matematika, dimana dilakukan uji hipotesis dengan uji-t diperoleh $\mathrm{T}$ (hitung) 4,586 > T(tabel) 2,045. Peningkatan ini didapat setelah siswa 
melalui proses pembelajaran dengan penerapan model pembelajaran CTL yang membuat siswa antusias dan aktif ikutserta berdiskusi dan bekerja sama dalam menyelesaikan permasalahan dalam LPKD. Hal tersebut menunjukkan bahwa model pembelajaran CTL dapat digunakan sebagai pilihan model pembelajaran yang dapat memberikan perubahan pada hasil belajar matematika siswa kelas IV.

Karena sebagian besar kesulitan belajar yang ditemui oleh setiap siswa bahan matematika pada pembelajaran online dibatasi oleh sinyal teknis dan ketidakmampuan untuk belajar online maka penelitian ini dilakukan secara offline namun tetap menggunakan prokes. Penelitian ini dilakukan bertujuan untuk mengetahui pengaruh dari permasalahan dalam pembelajaran dengan penyelesaian permasalahan menggunakan model pembelajaran, dan dapat dilhat berdasarkan data penilaian serta pengambilan data.

Terdapat perbedaan yang signifikan dalam permasalahan penelitian (Kistian, 2018) disebabkan karena proses penyampaian materi dalam pembelajaran. Pada penerapannya guru lebih cenderung mendorong siswa untuk menghafal namun tidak dikaitkan dalam kehidupan sehari sehingga berpengaruh dalam ranah kognitif siswa. Sehingga dalam penelitian ini solusi untuk menyelesaikan menggunakan model CTL dengan pembelajaran konvensional. Berdasarkan hasil uji hipotesis pada hasil belajar siswa diperoleh bahwa thitung 3,43 > t tabel 1,67, sehingga H0 ditolak dan H1 diterima artinya terdapat perbedaan hasil belajar yang signifikan pada ranah kognitif siswa antara model pembelajaran Contextual Teaching and Learning (CTL) dengan pembelajaran konvensional.

Dari hasil analisis diatas dapat dibuktikan bahwa penerapan model contextual teaching and learning dapat diterapkan dikehidupan sehari-hari sehingga siswa sudah tidak bingung dalam memecahkan permasalahan dan dapat diselesikan dengan sangat baik. Dengan menerapkan pembelajaran contextual teaching and learning dapat mengembangkan kemampuan siswa dalam memahami materi ajar dengan mengaitkan dalam kontesks kehidupaan nyata sehingga siswa dapat memperoleh pengetahuan dan keterampilan dalam memecahkan permasalahan yang didapat dalam materi pembelajaran.

\section{KESIMPULAN}

Hasil temuan dalam penelitian dan analisis data yang telah dilakukan dapat disimpulkan bahwa model pembelajaran CTL dapat mempengaruhi hasil belajar matematika siswa sehingga dapat diterapkan dengan suasana kelas yang aktif dan efektif. Berdasarkan deskripsi data penelitian diperoleh nilai rata-rata pre-test kelas IV C adalah 60,23, sedangkan nilai rata-rata kelas post-test kelas IV C adalah 84,63. Dari analisis data diperoleh $\mathrm{L}$ (hitung $)=0,1416$ dan $\mathrm{L}$ (tabel $)=0,1617$. Sedangkan uji normalitas hasil nilai post-test untuk taraf signifikan $\alpha=0,05$, diperoleh $\mathrm{L}$ (hitung $)=0,1562$ dan $\mathrm{L}$ (tabel ) $=0,1617$. Karena $\mathrm{L}$ (hitung ) $<\mathrm{L}($ tabel ), maka data penelitian menggunakan model pembelajaran Contextual Teaching and Learning berdistribusi normal. Dari analisis data Uji F diperoleh Fhitung $=1,029$ dan Ftabel $=1,850$. Karena Fhitung < Ftabel, maka data hasil nilai pretest dan posttest dinyatakan homogen. Dari analisis data akhir diperoleh Thitung $=4,586$ dan Ttabel $=2,045$ dengan taraf signifikan 5\%. Karena $\mathrm{t}($ hitung $)>$ dari $\mathrm{t}(\mathrm{tabel})$ hipotesis yang diajukan diterima. Artinya hipotesis Ha diterima yakni ada pengaruh signifikan pada hasil belajar siswa matematika setelah penerapan model pembelajaran CTL.

\section{UCAPAN TERIMA KASIH}

Peneliti mengucapkan terima kasih kepada Allah SWT, keluarga dan teman-teman yang telah membantu dan memberikan semangat serta doanya. Selanjutnya peneliti berterima kasih kepada pihak lainnya yang telah membantu dan memberikan kesempatan kepada peneliti untuk menyusun dan melakukan penelitian. Semoga penelitian ini dapat memberikan manfaat dan keberkahan untuk semua orang dalam kehidupan. 

Matematika Siswa Sekolah Dasar - Zahra Aulia Rahmah, Imas Ratna Ermawati DOI: https://doi.org/10.31004/basicedu.v6i1.1916

\section{DAFTAR PUSTAKA}

Amalia, Y., \& Rasiman, R. (2019). Pengaruh Model Ctl (Contextual Teaching Learning) Dengan Media Pohon Hitung Terhadap Hasil Belajar Materi Operasi Hitung. International Journal Of Elementary Education. Https://Doi.Org/10.23887/Ijee.V3i2.18525

Asriningtyas, A. N., Kristin, F., \& Anugraheni, I. (2018). Penerapan Model Pembelajaran Problem Based Learning Untuk Meningkatkan Kemampuan Berpikir Kritis Dan Hasil Belajar Matematika Siswa Kelas 4 Sd. Jipmat. Https://Doi.Org/10.26877/Jipmat.V3i1.2226

Dini, S. F., Sulistyarini, \& Anasi Putri Tipa. (2019). Pengaruh Penggunaan Model Project Citizen Terhadap Kemampuan Berpikir Kritis Siswa Dalam. Pengaruh Penggunaan Model Project Citizen Terhadap Kemampuan Berpikir Kritis Siswa, 1-9.

Fadhilaturrahmi, F. (2018). Peningkatan Hasil Belajar Siswa Pada Materi Jaring-Jaring Balok Dan Kubus Dengan Pendekatan Contextual Teaching And Learning (Ctl) Siswa Kelas Iv Sdn 05 Air Tawar Barat. Jurnal Basicedu, 1(1), 1-9. Https://Doi.Org/10.31004/Basicedu.V1i1.9

Handayani, E. S., \& Subakti, H. (2020). Pengaruh Disiplin Belajar Terhadap Hasil Belajar Bahasa Indonesia Di Sekolah Dasar. Jurnal Basicedu, 5(1), 151-164. Https://Doi.Org/10.31004/Basicedu.V5i1.633

Hidayati, N. M. \& M. (2018). Bukan Kelas Biasa. Surakarta: Kekata Publisher.

Imron, I. (2019). Analisa Pengaruh Kualitas Produk Terhadap Kepuasan Konsumen Menggunakan Metode Kuantitatif Pada Cv. Meubele Berkah Tangerang. Indonesian Journal On Software Engineering (Ijse), 5(1). Https://Doi.Org/10.31294/Ijse.V5i1.5861

Jihad, A. H. Dan A. (2013). Evaluasi Pembelajaran. Yogyakarta: Multi Pressindo.

Kistian, A. (2018). Pengaruh Model Pembelajaran Contextual Teaching And Learning (Ctl) Terhadap Hasil Belajar Matematika Siswa Kelas Iv Sd Negeri Langung Kabupaten Aceh Barat. Bina Gogik, 5(2).

Lestari, I. (2015). Pengaruh Waktu Belajar Dan Minat Belajar Terhadap Hasil Belajar Matematika. Formatif: Jurnal Ilmiah Pendidikan Mipa. Https://Doi.Org/10.30998/Formatif.V3i2.118

Novitasari, L. Dan L. (2017). Pengaruh Kemampuan Pemahaman Konsep Matematika Terhadap Hasil Belajar Matematika. Prosiding Diskusi Panel Nasional Pendidikan Matematika. Fakultas Teknik, Matematika, Dan Ilmu Pengetahuan Alam Universitas Indraprasta Pgri.

Rusman. (2018). Model-Model Pembelajaran: Mengembangkan Profesionalisme Guru. Depok: Rajawali Pers.

Siagian, G. (2021). Jurnal Basicedu. Jurnal Basicedu, 5(3), 1683-1688.

Siswanto. (2017). Penilaian Dan Pengukuran Sikap Dan Hasil Belajar Peserta Didik (Cet. 1). Klaten: Bossscript.

Siswono, T. Y. E. (2012). Belajar Dan Mengajar Matematika Anak Usia Dini. Universitas Negeri Surabaya Kampus Ketintang Surabaya 61231.

Soleha, F., Akhwani, A., Nafiah, N., \& Rahayu, D. W. (2021). Model Pembelajaran Contextual Teaching And Learning Untuk Meningkatkan Hasil Belajar Pkn Di Sekolah Dasar. Jurnal Basicedu, 5(5), 3117-3124. Https://Doi.Org/10.31004/Basicedu.V5i5.1285

Susanto, A. (2013). Teori Belajar Dan Pembelajaran Di Sekolah Dasar. Jakarta: Prenadamedia Group.

Widyaiswara, G. P., Parmiti, D. P., \& Suarjana, I. M. (2019). Pengaruh Model Pembelajaran Contextual Teaching And Learning Terhadap Hasil Belajar Ipa. International Journal Of Elementary Education, 3(4), 389. Https://Doi.Org/10.23887/Ijee.V3i4.21311 